Supplement of Ocean Sci., 13, 873-888, 2017 https://doi.org/10.5194/os-13-873-2017-supplement C Author(s) 2017. This work is distributed under the Creative Commons Attribution 3.0 License.

(c) (1)

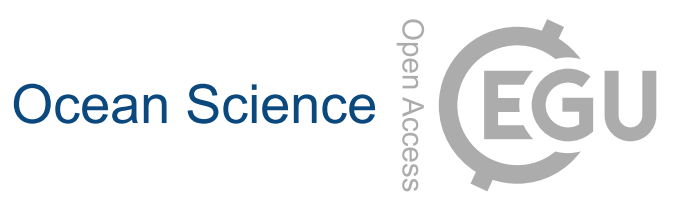

Supplement of

\title{
Atlantic water flow through the Faroese Channels
}

Bogi Hansen et al.

Correspondence to: Bogi Hansen (bogihan@hav.fo)

The copyright of individual parts of the supplement might differ from the CC BY 3.0 License. 
Table S1. Selected mooring sites of traditional (Aanderaa) current meters with number of deployments (Depl), total number of days with good data (Days), position and bottom depth (Botm), and magnitude (Speed) and direction (Dir) of the velocity at $40 \mathrm{~m}$ depth.

\begin{tabular}{lrrrrrrr}
\hline \multirow{2}{*}{ Site } & \multirow{2}{*}{ Depl } & \multirow{2}{*}{ Days } & \multicolumn{2}{c}{$\begin{array}{c}\text { Position } \\
\text { Latit. }\end{array}$} & Longit. & Botm & \multicolumn{2}{c}{$\begin{array}{c}\text { Speed } \\
\mathrm{Cm} \mathrm{s}^{-1}\end{array}$} & $\begin{array}{c}\text { Dir } \\
\circ\end{array}$ \\
\hline $\mathrm{CF}$ & 1 & 60 & 61.157 & -8.190 & 119 & 17.9 & 134 \\
$\mathrm{CW}$ & 7 & 831 & 61.717 & -7.483 & 148 & 6.6 & 340 \\
$\mathrm{CS}$ & 6 & 854 & 61.200 & -6.500 & 140 & 12.6 & 166 \\
$\mathrm{CE}$ & 14 & 2035 & 61.788 & -6.200 & 120 & 12.3 & 196 \\
\hline
\end{tabular}

Table S2. Selected ADCP sites with number of deployments (Depl), total number of days with good data (Days), position and bottom depth (Botm), and magnitude (Speed), direction (Dir), and stability (Stab) of the velocity at the depth indicated in column "Depth". The stability is the magnitude of the average velocity vector divided by the averaged velocity magnitude for each day so that a completely uni-directional flow (discounting tides) will have a stability of $100 \%$.

\begin{tabular}{lrrrrrrrrr}
\hline Site & Depl & Days & \multicolumn{2}{c}{ Position } & Botm & Depth & Speed \\
Latit. & Longit. & \multicolumn{1}{c}{$\begin{array}{c}\text { Dir } \\
\text { cm } \text { s }^{-1}\end{array}$} & $\begin{array}{c}\text { Stab } \\
\text { ○ }\end{array}$ \\
\hline EB & 2 & 456 & 61.6034 & -4.3366 & 787 & 200 & 12.1 & 202 & 68 \\
SA & 4 & 1106 & 61.0000 & -5.8567 & 293 & 200 & 3.3 & 196 & 48 \\
SB & 15 & 4312 & 60.7830 & -5.3000 & 786 & 200 & 3.2 & 173 & 18 \\
SX & 2 & 693 & 60.8612 & -5.4958 & 546 & 200 & 8.9 & 226 & 58 \\
SY & 3 & 951 & 60.7183 & -5.0983 & 897 & 200 & 7.4 & 169 & 35 \\
SC & 16 & 5003 & 60.5660 & -4.7663 & 1071 & 200 & 7.7 & 112 & 33 \\
SD & $31 *$ & 4519 & 60.4410 & -4.3620 & 801 & 200 & 19.5 & 67 & 67 \\
SE & $38 *$ & 5235 & 60.2830 & -4.3010 & 447 & 200 & 22.7 & 56 & 94 \\
ZQ & 1 & 257 & 60.8335 & -6.3925 & 169 & 100 & 5.6 & 235 & 55 \\
ZA & 2 & 684 & 60.3883 & -6.1600 & 417 & 200 & 0.5 & 213 & 3 \\
ZB & 2 & 599 & 60.2283 & -6.1667 & 1139 & 200 & 9.2 & 68 & 42 \\
ZC & 1 & 256 & 60.0683 & -6.1683 & 1080 & 200 & 22.7 & 92 & 79 \\
ZE & 1 & 145 & 59.9060 & -6.1670 & 775 & 200 & 16.4 & 119 & 79 \\
FG & 1 & 364 & 61.4710 & -8.2208 & 561 & 200 & 8.2 & 301 & 43 \\
FB & 20 & 6762 & 61.4159 & -8.2833 & 809 & 400 & 2.6 & 350 & 17 \\
FC & 15 & 4007 & 61.3935 & -8.3160 & 836 & 300 & 10.8 & 126 & 68 \\
\hline
\end{tabular}

*Includes ADCP data from the North West Approaches Group.

Table S3. Correlation coefficients $(\mathrm{R})$ between weekly averaged along-channel velocities from all pairs of simultaneous ADCP deployments over the Faroese slope. The terms „Upstream“ and „Downstream“ refer to a flow direction from the Faroe-Shetland Channel towards the Faroe Bank Channel. Each deployment is characterized by the site (Figure 2 in manuscript), the selected depth, and the along-channel direction („tow.“ „toward“). „Days“ indicates the number of values before averaging. None of the correlation coefficients are statistically significant.

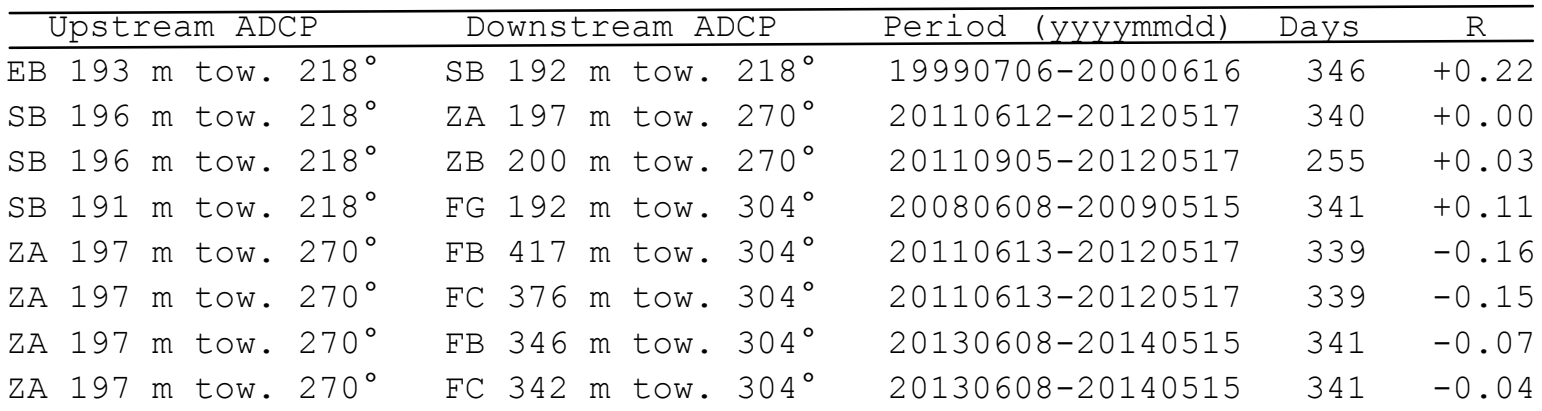




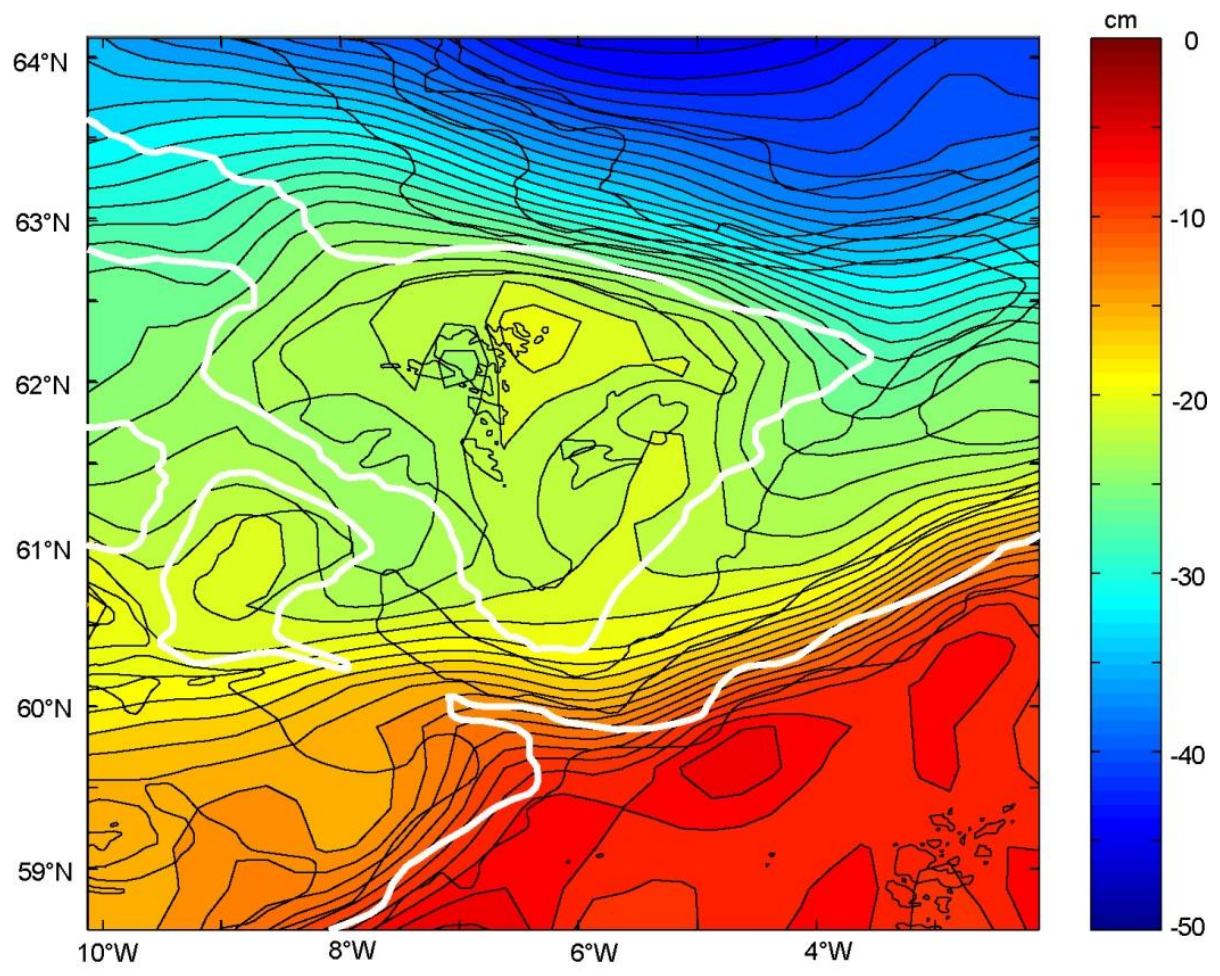

Figure S1. Mean Dynamic Topography in the region. The bottom topography is shown by thin black lines with the $500 \mathrm{~m}$ bottom contour in white.

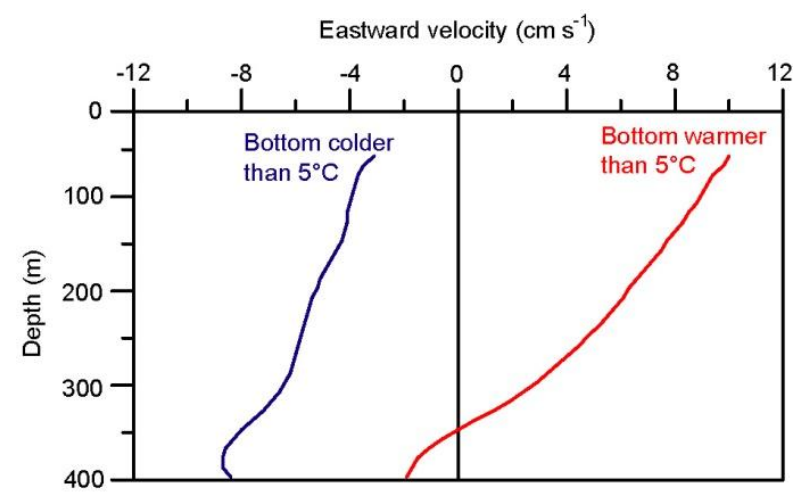

Figure S2. Average velocity profiles at site ZA (bottom depth $416 \mathrm{~m}$ ) during the two deployments split into periods with bottom temperature below (blue, 389 days) and above (red, 295 days) $5{ }^{\circ} \mathrm{C}$. 

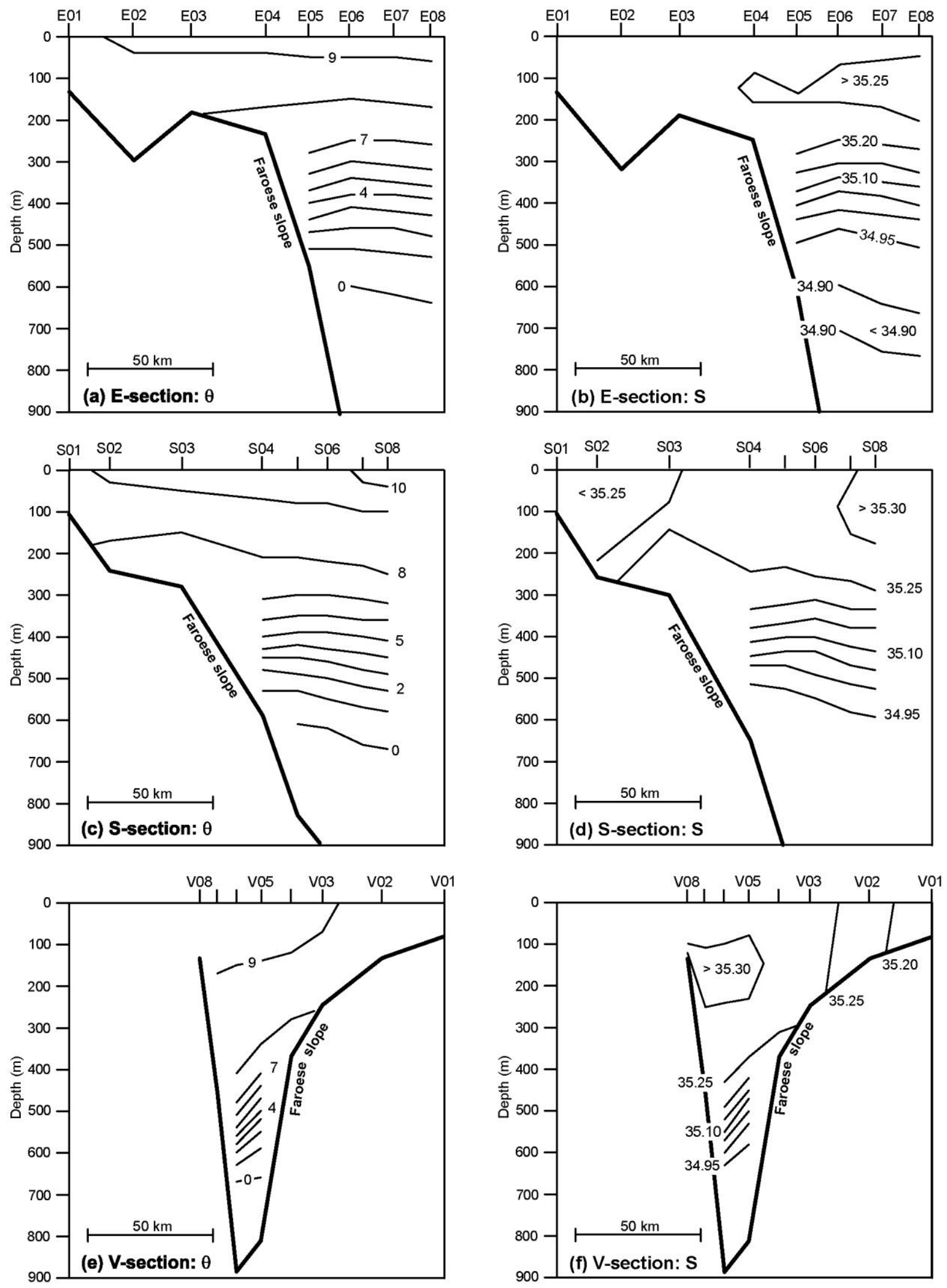

Figure S3. Average distributions of potential temperature $(\theta, \mathbf{a}, \mathbf{c}, \mathbf{e})$ and salinity $(\mathrm{S}, \mathbf{b}, \mathbf{d}, \mathbf{f})$ on three sections (Figure 2a in manuscript) showing the 8 closest standard stations to the Faroes for each section. Based on 47 cruises by R/V Magnus Heinason 1996-2015, on which all three sections were occupied within one week. 

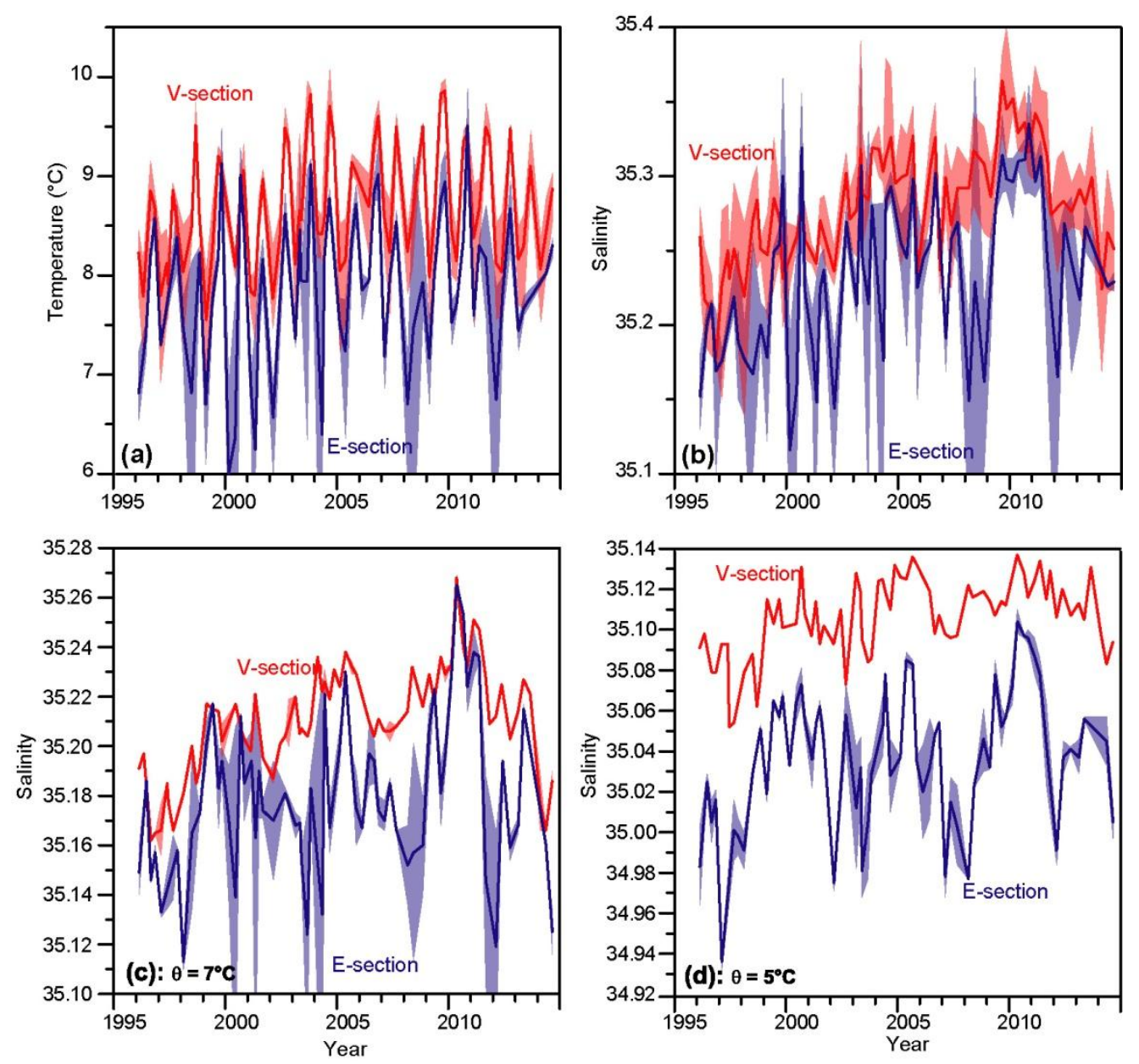

Figure S4. Water mass comparison between water over the Faroese slopes in the Faroe Bank Channel (Vsection) and the Faroe-Shetland Channel (E-section), respectively (Figure 2a in the manuscript). The top two panels compare temperature (a) and salinity (b) averaged between $100 \mathrm{~m}$ and $200 \mathrm{~m}$ depth for three standard stations (V03, V04, V05 with bottom depths $239 \mathrm{~m}, 354 \mathrm{~m}, 807 \mathrm{~m}$ ) on the V-section (red) with three stations (E04, E05, E06 with bottom depths $230 \mathrm{~m}, 539 \mathrm{~m}, 988 \mathrm{~m}$ ) on the E-section (blue). The bottom panels show salinities at fixed potential temperatures $7{ }^{\circ} \mathrm{C}(\mathbf{c})$ and $5{ }^{\circ} \mathrm{C}(\mathbf{d})$ for the same stations. In each case, the average of the three stations for each cruise is shown by the thick red/blue line surrounded by a red/blue area indicating the range from minimum to maximum. To enhance visibility of differences, temperatures less than $6{ }^{\circ} \mathrm{C}$ and salinities less than 35.1 have been clipped in panels $\mathbf{a}, \mathbf{b}$, and $\mathbf{c}$. 

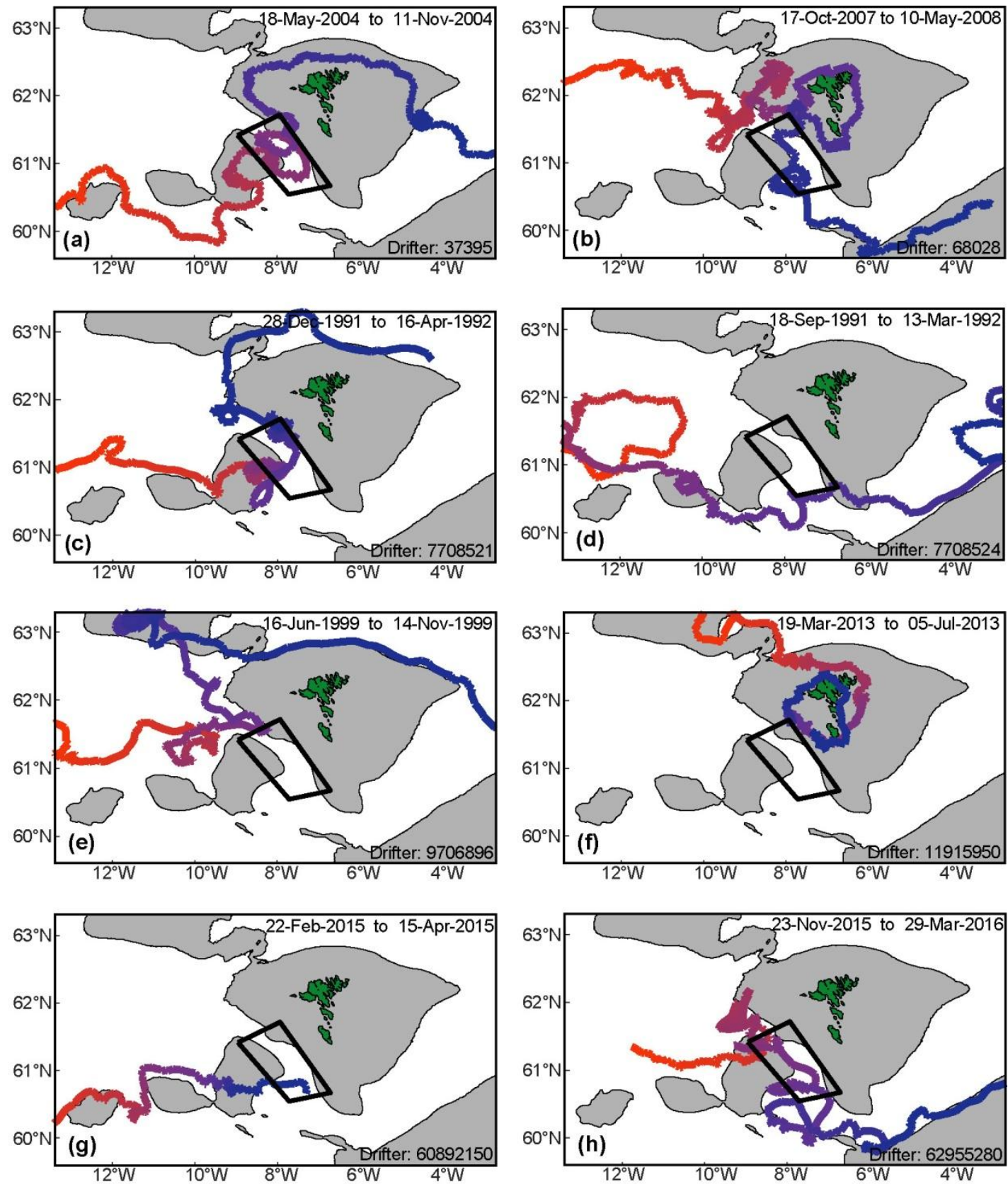

Figure S5. Tracks of all the surface drifters that entered the Faroe Bank Channel, here defined by the black polygon shown on each panel. The tracks are colour-coded with time so that they are red in the beginning, turning to blue at the end. 

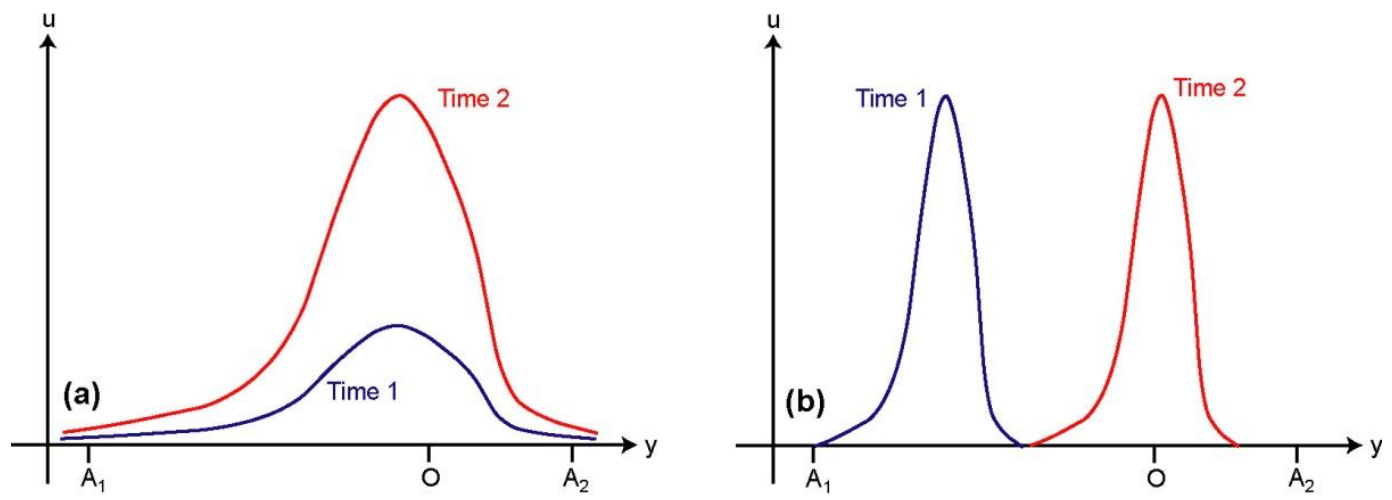

Figure S6. Two conceptual examples to illustrate the relationship between surface current velocity measured by current meter (e.g., ADCP) or by altimetry. Both panels show eastward surface current (u) plotted against the ycoordinate (northward) at two different times. $\mathrm{A}_{1}$ and $\mathrm{A}_{2}$ are two altimetry grid points between which the horizontally averaged velocity $u_{A}(t)$ can be derived assuming geostrophy. $\mathrm{O}$ is a point at which the surface current $u_{O}(t)$ is measured by current meter. In (a), we assume that the horizontal structure of the surface velocity is perfectly consistent so that the spatial and temporal variation may be separated: $u(y, t)=\varphi(y) \cdot \psi(t)$. In this case, both $u_{A}(t)$ and $u_{O}(t)$ will be proportional to $\psi(t)$ and hence proportional to one another. If all measurements and geostrophic balance are perfect, the correlation coefficient between $u_{A}(t)$ and $u_{O}(t)$ will be 1 . The regression coefficient $\alpha$ in Eq. (1) in the main manuscript will be higher the closer $O$ is to the core of the current. At the core, it will be well above the theoretical value. With noisy data and/or ageostrophic flow, the correlation coefficient will be less than 1, but will be highest close to the core. In (b), we assume a narrow surface current, for which the strength does not vary with time, but the current moves back and forth laterally. In this case, $u_{A}(t)$ will be constant whereas $u_{O}(t)$ varies. With perfect measurements and geostrophy, the correlation coefficient between $u_{A}(t)$ and $u_{O}(t)$ will be 0 .
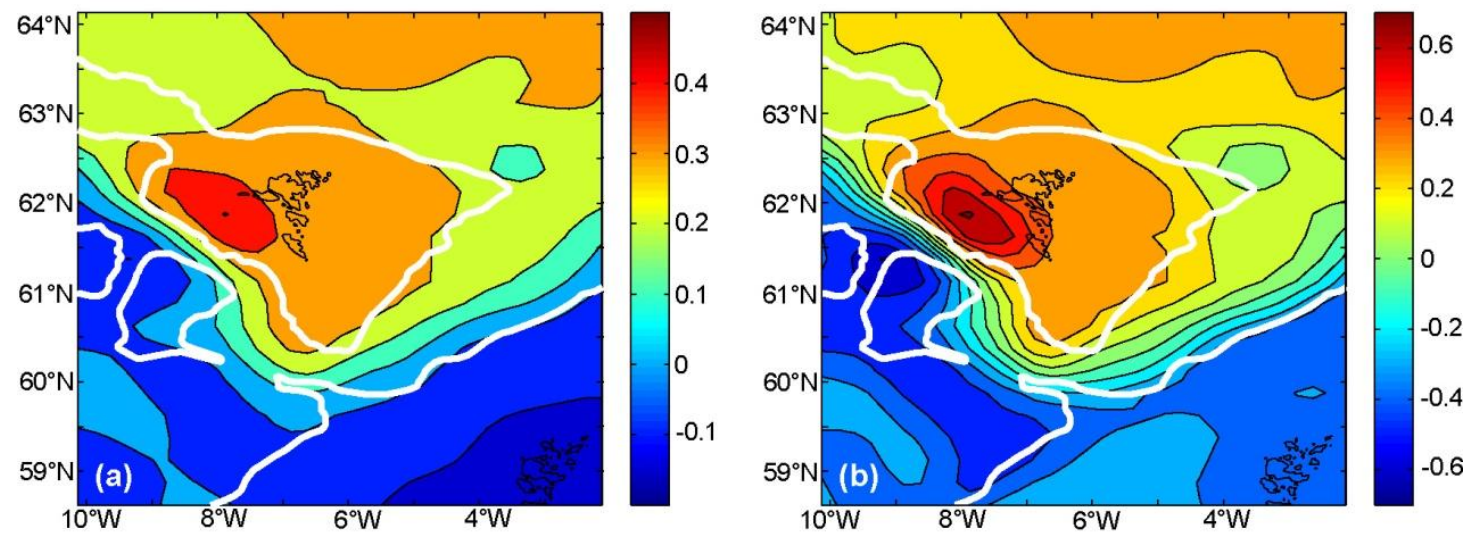

Figure S7. The difference between using SLA and SLA*. (a) Correlation coefficient between $\triangle S L A_{F B C}$ and SLA at all grid points of the region. (b) Correlation coefficient between $\triangle S L A_{F B C}$ and SLA* at all grid points of the region. 

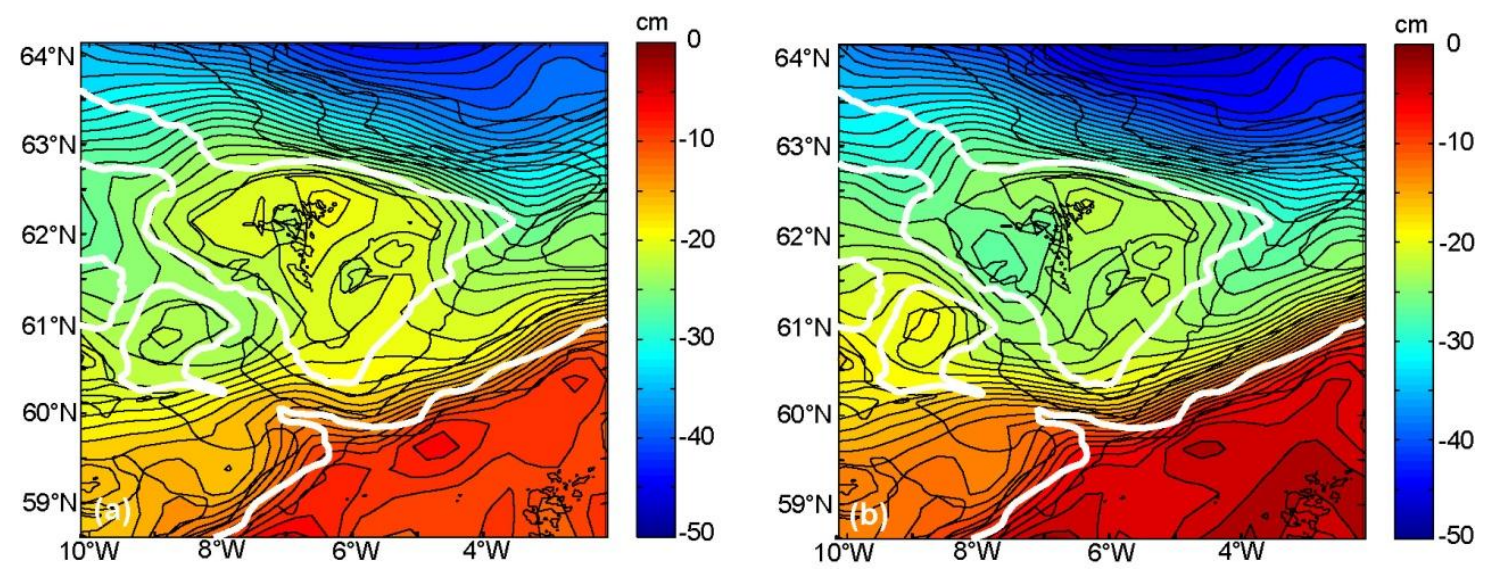

Figure S8. (a) Average MDT+SLA* when $\triangle S L A_{F B C} \geq+1$ standard deviation. (b) Average MDT+SLA* when $\triangle S L A_{F B C} \leq-1$ standard deviation. MDT is Mean Dynamic Topography. The thick white lines indicate the $500 \mathrm{~m}$ bottom contour. 

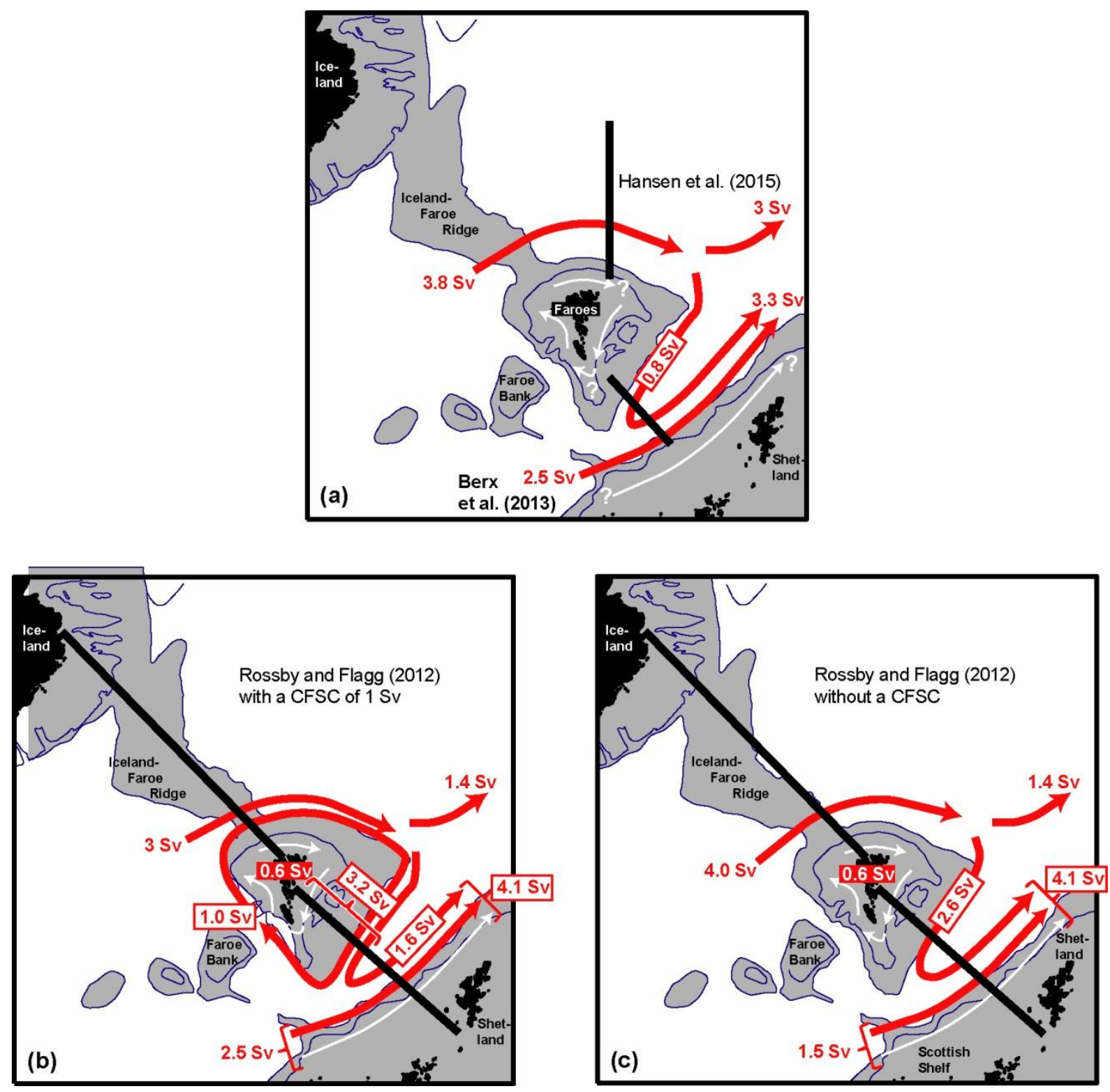

Figure S9. Atlantic inflow between Iceland and Scotland (thick red arrows) March 2008 to March 2011 in three recent studies using two different methods. (a) According to Berx et al. (2013) and Hansen et al. (2015). (b, c) According to Rossby and Flagg (2012) with (b) and without (c) a Circum-Faroe Slope Current (CFSC) of 1 Sv. Rossby and Flagg (2012) find a closed circulation on the Faroe Shelf of 0.6 Sv (white arrows), which is not included in the estimates by Berx et al. (2013) and Hansen et al. (2015). In addition, Rossby and Flagg (2012) assume a closed CFSC of $1 \mathrm{~Sv}$ (b), which implies an inflow to the Faroe-Shetland Channel from the West of 2.5 Sv in close agreement with Berx et al. (2013). Without the CFSC (c), the inflow from the West is reduced to 1.5 Sv including flow over the Scottish Shelf that is not included in Berx et al. (2013). 